\title{
Effects of a 6-month multimodal training intervention on retention of functional fitness in older adults: A randomized-controlled cross-over design
}

Janus Gudlaugsson ${ }^{1}$, Vilmundur Gudnason ${ }^{2,3}$, Thor Aspelund ${ }^{2,3}$, Kristin Siggeirsdottir ${ }^{2}$, Anna S Olafsdottir ${ }^{1}$, Palmi V Jonsson ${ }^{3,4}$, Sigurbjorn A Arngrimsson ${ }^{1}$, Tamara B Harris ${ }^{5}$ and Erlingur Johannsson ${ }^{1 *}$

\begin{abstract}
Background: Older adults have the highest rates of disability, functional dependence and use of healthcare resources. Training interventions for older individuals are of special interest where regular physical activity (PA) has many health benefits. The main purpose of this study was to assess the immediate and long-term effects of a 6-month multimodal training intervention (MTI) on functional fitness in old adults.

Methods: For this study, 117 participants, 71 to 90 years old, were randomized in immediate intervention group and a control group (delayed intervention group). The intervention consisted of daily endurance and twice-a-week strength training. The method was based on a randomized-controlled cross-over design. Short Physical Performance Battery (SPPB), 8 foot up-and-go test, strength performance, six min walking test (6 MW), physical activity, BMI and quality of life were obtained at baseline, after a 6-month intervention- and control phase, again after 6-month crossover- and delayed intervention phase, and after anadditional 6-month follow-up.

Results: After 6 months of MTI, the intervention group improved in physical performance compared with the control group via Short Physical Performance Battery (SPPB) score (mean diff $=0.6,95 \%$ Cl: 0.1, 1.0) and 8-foot up-and-go test (mean diff $=-1.0 \mathrm{~s}, 95 \% \mathrm{Cl}:-1.5,-0.6$ ), and in endurance performance via 6-minute walking test (6 MW) (mean diff $=44.2$ meters, $95 \% \mathrm{Cl}: 17.1,71.2)$. In strength performance via knee extension the intervention group improved while control group declined (mean diff $=55.0$ Newton, $95 \%$ Cl: 28.4, 81.7), and also in PA (mean diff $=125.9 \mathrm{cpm}, 95 \% \mathrm{Cl}: 96.0,155.8)$. Long-term effects of MTI on the particpants was assesed by estimating the mean difference in the variables measured between time-point 1 and 4: SPPB (1.1 points, $95 \%$ Cl: 0.8, 1.4); 8-foot up-and-go (-0.9 s, 95 \% Cl: -1.2, -0.6); 6 MW (18.7 m, 95 \% Cl: 6.5, 31.0); knee extension (4.2 Newton, 95 \% Cl: -10.0, 18.3); hand grip (6.7 Newton, $95 \%$ Cl: $-4.4,17.8) ;$ PA (-4.0 cpm, 95 \% Cl: $-33.9,26.0) ; B M l\left(-0.6 \mathrm{~kg} / \mathrm{m}^{2}, 95\right.$ \% Cl: -0.9 , $-0.3)$ and Icelandic quality of life $(0.3$ points, $95 \% \mathrm{Cl}:-0.7,1.4)$.
\end{abstract}

Conclusions: Our results suggest that regular MTI can improve and prevent decline in functional fitness in older individuals, influence their lifestyle and positively affect their ability to stay independent, thus reducing the need for institutional care.

Trial registration: This study was approved by the National Bioethics Committee in Iceland, VSNb20080300114/03-1 Keywords: Physical activity, Functional fitness, SPPB, 6 MW, Strength, Cross-over design

\footnotetext{
* Correspondence: erljo@hi.is

${ }^{1}$ Centre for Research in Sport and Health Sciences, University of Iceland,

Laugarvatn, Iceland

Full list of author information is available at the end of the article
} 


\section{Background}

Older adults have the highest rates of disability, functional dependence and use of healthcare resources, so effective interventions for older individuals are of special interest [1,2]. Regular physical activity (PA) has many health benefits for older people, contributing to a healthy and independent lifestyle and improvements in functional capacity, quality of life, and body composition [3-5]. Regular multimodal training, based on combined endurance and strength exercise, can also minimize the physiological effects of an otherwise sedentary lifestyle by reducing the development and progression of chronic disease and disabling conditions [6,7].

Several recent multimodal training studies have focused on the detraining effect where the outcome is a loss in performance with onset as soon as six weeks after training [8-10]. Others have reported follow-up results based on multimodal training intervention and how changes in PA behavior can influence older people's lifestyles [11-13]. However, the current literature on multimodal training studies is conflicting in regards to individual responsibility, practical knowledge, and skills. Moreover, few have investigated how multimodal training programs can influence older people's long-term lifestyle [11-13].

To the best of our knowledge, few trials of randomized-controlled cross-over design using international recommendations with an emphasis on daily endurance and twice-a-week strength training [14], individual responsibility, practical knowledge, and skills have focused on 70-90 years old people for a 6-month extended follow-up. Therefore the main purpose of this training study was firstly to evaluate the long-term effects, 6 and 12 months following the completion of a 6-month multimodal training intervention (MTI) on functional performance, endurance performance via 6 minute walk test, strength, PA, BMI and Icelandic quality of life (IQL) in older persons, and secondly to analyze the short-term effects on outcomes after the completion of the intervention.

\section{Methods}

\section{Study design}

This study was a randomized, controlled, cross-over design, performed in Reykjavik, the capital area of Iceland. The trial was conducted in four phases (timepoints): 1) Enrolment and the baseline assessment, where the participants were randomized into an immediate training intervention group (Group 1) and a delayed intervention group (Group 2), 2) the immediate intervention phase, where Group 1 underwent training for 6 months and Group 2 served as a control group, 3) the crossover- and delayed intervention phase in which participants in Group 2 received the same training intervention for 6 months as Group 1 received, which from that time-point did not receive any further intervention, and 4) additional 6-month follow-up without intervention (Figure 1). Outcome assessments occurred at the end of the immediate intervention and control phase, at the end of the crossover and delayed intervention phase, and after an additional 6 months follow-up phase.

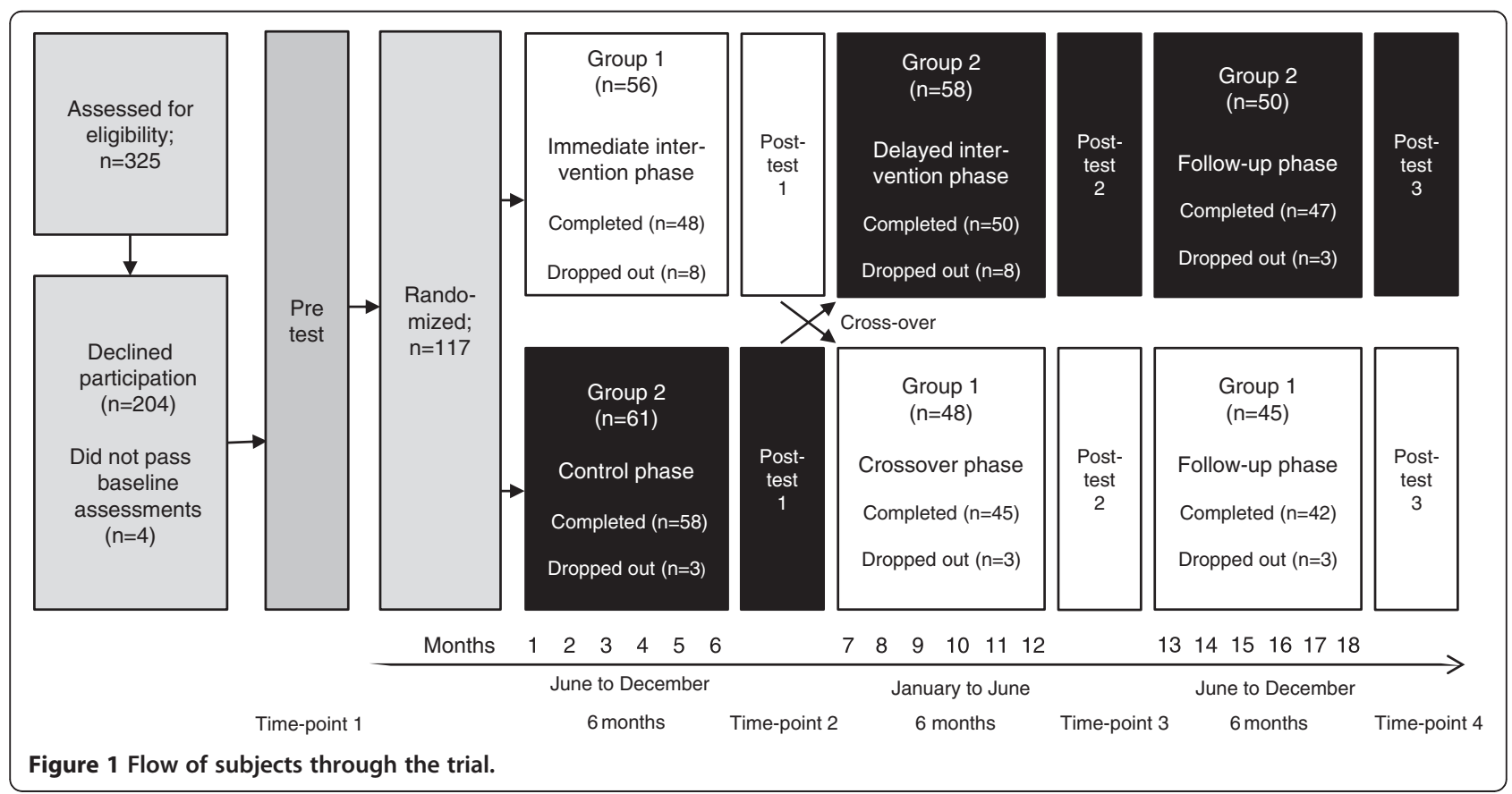




\section{Study participants}

The participants were older individuals selected from the population-based Age, Gene/Environment Susceptibility AGES Reykjavik Study [15] among individuals who were cognitive competent. Those who obtained a score of $\geq 23$ points on the Mini Mental State Examination (MMSE) and $\geq 17$ points on the Digit Symbol Substitution Test (DSST) were eligible for selection. Ninetytwo of the 325 older individuals (>70), along with 25 spouses, accepted the invitation. Each participant in the trial had to fill out a questionnaire about his or her general health, and the information was reviewed by the study physician with regard to the safety of prescribed exercise. The Short Physical Performance Battery test (SPPB) [16] was also performed at screening, and a score of at least 7 points out of 12 on the test was required to be eligible for the study. The study was powered to detect a medium effect size ( $0.25 \mathrm{SD}$ units) of any outcome measure with $80 \%$ probability, using ANCOVA to compare the post intervention measurements adjusting for baseline, not taking the clustering within groups into account. The sample size estimated was 100 at the end of the study period. We assumed a participation rate of $75 \%$ and due to the length of the study we assumed an attrition rate of about $20 \%$.

\section{Physical exercise intervention}

The intervention consisted of a 6-month multimodal training, with an emphasis on daily endurance training and twice-a-week strength training. This was supported by seven lectures, three on nutrition and four on healthy aging, endurance, strength and how to train.

The endurance training consisted of daily walking over the intervention phase. The duration of the training session increased progressively through the 6month training period. During the first week, the participants trained for 20 minutes at each session, and then the duration was increased systematically over the training period with two recovery weeks. The average duration per day was estimated at 34 minutes. In the first and last eight weeks, a health instructor was on site twice a week, but in weeks 9-18, only once a week. The training took place outdoors on a 400-meter running track, except for four weeks during the winter period when the training was indoors. Other endurance training sessions were self-administered with participants following the training intervention plan from the program. A health instructor was on site once to twice-aweek, but other endurance training sessions were selfadministered with participants following a training plan, using the Karvonen formula to maintain and gradually increase the intensity [17]. During the first eight weeks, the intensity level was $50 \%$ of heart rate reserve (HRR), for the next 10 weeks it was increased to $60 \%$, and during the last eight weeks it was approximately $70 \%$ of HRR. Every participant wore a Polar heart-rate monitor to maintain his or her individual target heart rate during the training.

Resistance training took place twice-a-week, on Tuesdays and Fridays, in a fitness centre, using the circuit series strength equipment from Life Fitness (Circuit Series Strength, Brunswick Corporation, USA), always under the guidance of health instructors. The strength training consisted of 12 exercises for all major muscle groups and was individually-based following a systematic training plan. The focus was on strength-endurance training for the first 3 months but for the latter 3 months it was on strength-power. The exercises for the lower body included leg press, leg extensions and calf raises. Exercises for the upper body included bench press, chest cross, shoulder press, pull downs, biceps curls, triceps extensions, and exercises for abdominal muscles and the back. For the first 2 weeks of strength-endurance training, the training program consisted of two sets of 12 repetitions $(2 \times 12)$ at $50 \%$ of one repetition maximum (1RM). Every two weeks, the working load was increased by two repetitions. The strength-endurance training was done in form of circuit training program, one set at each time. In the $13^{\text {th }}$ week the repetitions were 18 in two sets. Recovery in form of light stretching between circuits was 3-4 minutes. In the second period, weeks 14 to 26 , there program was changes from strength-endurance program to strength-power training program. The intensity went systematically from 10RM repetitions in the $14^{\text {th }}$ week down to $6 R M$ in the $24^{\text {th }}$ week. The power training program consisted from the same 12 exercises as described before. The participants finished their exercise, two sets, with 1.5 minute rest between each set. The $9^{\text {th }}$ and $18^{\text {th }}$ week was organized as recovery weeks, with no strength training but 20 minutes endurance training every day.

\section{Measurements}

Baseline measurements were performed over a two week period before randomization. Outcome data for Group 1 was collected at the end of the immediate intervention phase, after the completion of the 6-month crossover phase, and after a 6-month follow-up phase. Outcome data for Group 2 were collected after the control phase, after the delayed intervention phase and after the completion of a 6-month follow-up phase. Demographic and clinical data was collected by trained research staff.

The SPPB [16] was used to measure physical performance but mobility and balance were measured by the 8-foot up-and-go test [18]. Maximal isometric muscle strength of the thigh and hand on the dominant side was measured with the participant in a sitting position in an adjustable dynamometer chair (Good Strength, 
Metitur, Palokka, Finland) [19]. Knee extension was measured with the knee angle at $60^{\circ}$, the ankle fastened by a belt to a strain-gauge system and with the participant's hands gripping the edge of the seat. Handgrip strength was measured with a dynamometer fixed to the arm of the same chair with the elbow flexed at $90^{\circ}$, using the same instructions and methods as for the lower limbs. Endurance performance was measured using the 6-minute walk test (6 MW) according to a standardized protocol [20]. The heart rate of participants was measured before and directly after completing the walk, and once more one minute later.

Total PA was assessed with Actigraph accelerometers (AG; Model 7164, version 2.2; ActiGraph Health Services, Fort Walton Beach, Florida, USA), which were programmed to record PA over one-minute intervals (60s epoch) [21]. The accelerometers were worn on the hip for six consecutive days, four week days and two weekend days, from the time the participant woke up until he or she went to sleep. Only data from monitors worn a minimum of eight hours per day, for at least two weekdays and one weekend day were included in the analysis. Average counts per minute (cpm) for these days measured by the accelerometer were calculated for each participant and were used to estimate PA level. A questionnaire was also used to estimate PA behavior in a typical week at each measurement timepoint. During the training period, each participant had a 6-month intervention diary in which he or she had notes about suggested training regimens, but also confirmed their daily PA behavior as time spent on walking and strength training. The questionnaire and participant's diary were based on a Global Physical Activity Questionnaire [22].

Standing height was measured to the nearest $0.1 \mathrm{~cm}$ with a portable stadiometer (Seca 206, Seca Ltd, Birmingham, UK). Body weight was determined to the nearest $0.1 \mathrm{~kg}$ using a calibrated scale (Seca HV120, Seca Ltd, Birmingham, UK) with the participant in light clothing. Body mass index (BMI) was calculated as body mass $(\mathrm{kg})$ divided by height squared $\left(\mathrm{m}^{2}\right)$.

The health-related quality of life (HRQL) was measured with a validated generic Icelandic instrument, Icelandic Quality of Life questionnaire (IQL). The IQLtest has norms for males and females in different age groups in order to evaluate individual deviation in HRQL. Five factors explain two thirds of the variance: general health (23.4\%), mental well-being (20.5\%), satisfaction (9.0\%), sleep (6.9\%), and finance (6.3\%) [23].

\section{Statistical analysis}

Difference in each outcome at baseline and progression over time was analyzed using a repeated measures model with a first-order autoregressive covariance structure. A parameter was included in the model to represent each time-point for the immediate group (I), Group 1, and the delayed intervention group (D), Group 2: $\mu_{\mathrm{I} 1}, \mu_{\mathrm{I} 2}, \mu_{\mathrm{I} 3}, \mu_{\mathrm{I} 4}, \mu_{\mathrm{D} 1}, \mu_{\mathrm{D} 2}, \mu_{\mathrm{D} 3}, \mu_{\mathrm{D} 4}$. An adjustment was made for age and sex. The mixed models method allows for missing values in the response. All participants had at least a baseline measure and a measure after the intervention. Participants with missing values at other time-points were included in the analysis. Contrasts between time-points were estimated from linear combinations of the model parameters. For example: The difference between groups at baseline was estimated as $\mu_{\mathrm{I} 1}-\mu_{\mathrm{D} 1}$; the immediate intervention effect was estimated as $\mu_{\mathrm{I} 2}-\mu_{\mathrm{I} 1}$; the change between the repeat baseline and the baseline for the delayed intervention group was estimated as $\mu_{\mathrm{D} 2}-\mu_{\mathrm{D} 1}$; the delayed intervention effect as $\mu_{\mathrm{D} 3}-\mu_{\mathrm{D} 2}$; the overall intervention effect as $\left(\mu_{\mathrm{I} 2}-\mu_{\mathrm{I} 1}+\mu_{\mathrm{D} 3}-\mu_{\mathrm{D} 2}\right) / 2$; and the overall improvement completed follow-up phase by both groups (the difference between time-point 4 and time-point 1$)$ as $\left(\mu_{\mathrm{I} 4}-\mu_{\mathrm{I} 1}+\mu_{\mathrm{D} 4}-\mu_{\mathrm{D} 1}\right) / 2$. The results were generated using the SAS MIXED model procedure in SAS/STAT software, version 9.2.

\section{Results}

\section{Baseline characteristics and dropout}

A diagram of subjects' flow through this randomized cross-over trial detailing the measurement phases is illustrated in Figure 1. Out of the 325 who were potentially eligible, 121 (37\%) accepted the participation. The major reason for refusing participation in the study was too long and binding periods, not interested or because of spouse illness. Four participants out of the $121 \mathrm{did}$ not pass the baseline assessments of the study. Thus, 117 subjects were randomized to the immediate intervention group (Group 1; $\mathrm{n}=56$ ) and delayed intervention group (Group 2; $\mathrm{n}=61$ ). A total of 48 subjects, $85.7 \%$ of those randomized for Group 1, completed the immediate intervention phase, and a total of 50 subjects, $82 \%$ of those randomized for Group 2, completed the delayed intervention. Overall, 98 subjects out of the 117 who were randomized received the entire 6-month training intervention. Reasons for attrition included spouse's illness or lack of time due to commitment to family. Significant differences at baseline characteristics were seen in age between the 98 subjects who completed the 6-month MTI $(78.9 \pm 4.5)$ and the 19 subjects who were randomized but did not complete the intervention (82.6 \pm 3.5$)$, in 8 -foot up-and-go test $(6.3 \pm 1.2$ seconds by MTI vs $7.4 \pm 1.3$ seconds; $p<.01)$, and in strength, kneeextension (340.6 \pm 94.3 Newton by MTI vs $273.6 \pm 70.9$ Newton; $p<.05)$.

The baseline data for the characteristics of the study subjects randomized to Group 1 and Group 2 are 
Table 1 Baseline characteristics of subjects randomized to immediate intervention (Group 1) and delayed intervention (Group 2)

\begin{tabular}{|c|c|c|c|}
\hline \multirow[b]{3}{*}{ Characteristic } & \multirow{2}{*}{$\begin{array}{c}\text { Immediate intervention } \\
\text { Group } 1\end{array}$} & \multirow{2}{*}{$\begin{array}{c}\text { Delayed intervention (Control) } \\
\text { Group } 2 \\
\end{array}$} & \multirow{2}{*}{$\begin{array}{l}\text { Difference between } \\
\text { groups at baseline }\end{array}$} \\
\hline & & & \\
\hline & (n) Mean \pm SD (Range) & (n) Mean \pm SD (Range) & $p$-value \\
\hline Age & (56) $80.8 \pm 4.7(73-90)$ & (61) $78.3 \pm 4.1(71-88)$ & .003 \\
\hline Male (age) & (25) $81.9 \pm 4.8(75-90)$ & (29) $79.0 \pm 4.3(71-88)$ & .024 \\
\hline Female (age) & (31) $79.9 \pm 4.6(73-89)$ & (32) $77.8 \pm 3.8(72-85)$ & .045 \\
\hline \multicolumn{4}{|l|}{ Physical performance } \\
\hline SPPB (points) & (56) $10.1 \pm 1.5(7-12)$ & (61) $10.0 \pm 1.3(7-12)$ & .168 \\
\hline Balance (points) & (56) $3.3 \pm 0.8(2-4)$ & (61) $3.2 \pm 0.9(1-4)$ & .167 \\
\hline Walk (seconds) & (56) $3.7 \pm 0.9(2.3-8.4)$ & (61) $3.6 \pm 0.5(2.7-4.9)$ & .549 \\
\hline Chair (seconds) & (56) $12.8 \pm 2.5(7.7-18.0)$ & (61) $13.2 \pm 2.6(8.4-20.0)$ & .177 \\
\hline 8 foot up-and-go (seconds) & (56) $6.4 \pm 1.4(4.4-13.2)$ & (61) $6.5 \pm 1.1(4.4-9.7)$ & .217 \\
\hline \multicolumn{4}{|l|}{ Strength performance } \\
\hline Knee extension (Newton) & (56) $328.4 \pm 96.3(127.1-547.5)$ & 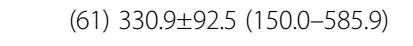 & .340 \\
\hline Hand grip (Newton) & (56) $311.0 \pm 96.8(168.4-567.0)$ & (61) $341.9 \pm 108.4(132.9-619.4)$ & .193 \\
\hline \multicolumn{4}{|l|}{ Endurance performance } \\
\hline Six min walking (meter) & 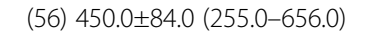 & (61) $459.8 \pm 64.8(300.0-612.0)$ & .592 \\
\hline Physical activity (cpm) & (39) $258.8 \pm 122.9(100.0-589.0)$ & (44) $253.9 \pm 101.8(106.0-537.0)$ & .275 \\
\hline BMI $\left(\mathrm{kg} / \mathrm{m}^{2}\right)$ & (56) $27.6 \pm 5.3(20.6-45.9)$ & (61) $27.4 \pm 3.4(20.1-36.3)$ & .406 \\
\hline Icelandic Quality of Life (points) & (54) $55.7 \pm 5.5(40-64)$ & (57) $55.9 \pm 5.1(38-63)$ & .574 \\
\hline
\end{tabular}

Values are shown as numbers in groups $(n)$, means with standard deviation (SD) and range.

$\mathrm{SD}=$ Standard deviation.

$\mathrm{SPPB}=$ Short physical performance battery.

$\mathrm{cpm}=$ Average counts per minute.

$\mathrm{BMI}=$ Body mass index

summarized in Table 1 . The mean age was approximately 80 and the range $71-90$. The only significant baseline difference between the two groups was in age, $80.8 \pm 4.7$ in Group 1 vs $78.3 \pm 4.1$ in Group 2 .

The immediate intervention phase and the control phase The results of the immediate intervention phase of the trial are presented in Table 2. There was a significant difference between the intervention and control groups in the changes for physical performance including better overall scores for the SPPB (mean diff $=0.6, p<.05$ ) and chair rises (mean diff $=-1.8 \mathrm{~s}, p<.001$ ), in mobility and balance by the 8 -foot up-and-go test (mean diff $=-1.0 \mathrm{~s}, p<.001$ ), in knee extension strength (mean diff $=55.0$ Newton, $\mathrm{p}<.001)$ and in endurance by the 6 -minute walking test (mean diff $=44.2 \mathrm{~m}, p<.001$ ). There were also significant increases in daily PA (mean diff $=125.9 \mathrm{cpm}, p<.001$ ) between the groups where the immediate intervention group increased their PA around $13 \%$ while at the same time the delayed intervention group showed a $14 \%$ decrease. Significant changes between baseline and MTI within the immediate intervention group was seen on all measurements apart from balance part in the SPPB and IQL.
The crossover and delayed intervention phase

The results of the crossover phase of the trial are presented in Table 3. Group 2 had improvements in their delayed intervention (Table 3, column 6) comparable to the immediate intervention of Group 1 (Table 2, column $3)$. In addition, all gains seen in the immediate intervention by Group 1 were maintained over the following 6-month period where there was no formal training on behalf of the health educators (Table 3, column 3).

\section{Multimodal training intervention phase by both groups together}

The effects of MTI in all 98 subjects in both Group 1 and Group 2 who completed the intervention are pooled together and summarized in Table 4. All changes in all measurements were statistically significant except for the balance test in SPPB. This may have represented a ceiling effect because approximately $58 \%$ of the subjects obtained 4 points or the maximum results from this test.

Figure $2 \mathrm{a}-\mathrm{c}$ demonstrates outcome measures at four time-points and MTI overall effect from both groups in long-term improvements in 8-foot up-and-go (mean diff = $-0.9, p<.001$ ) and $6 \mathrm{MW}$ (mean diff $=18.7 \mathrm{~m}, p<.01$ ), but strength performance measured as knee extension 
Table 2 Outcomes for subjects who completed the immediate intervention phase and the control phase, and between-group differences

\begin{tabular}{|c|c|c|c|c|c|c|c|}
\hline \multicolumn{4}{|c|}{ Group 1 (Immediate intervention phase) $(n=48)$} & \multicolumn{3}{|c|}{ Group 2 (Control phase) $(n=58)$} & \multirow{2}{*}{$\begin{array}{c}\text { Between-group } \\
\text { difference }\end{array}$} \\
\hline Outcome and Values & Baseline & MTI & Change & Baseline & Rep. Base & Change & \\
\hline & $\begin{array}{l}\text { Mean } \\
\text { (SE) }\end{array}$ & $\begin{array}{l}\text { Mean } \\
\text { (SE) }\end{array}$ & $\begin{array}{l}\text { Diff in means } \\
(95 \% \mathrm{Cl})\end{array}$ & $\begin{array}{l}\text { Means } \\
\text { (SE) }\end{array}$ & $\begin{array}{c}\text { Means } \\
\text { (SE) }\end{array}$ & $\begin{array}{l}\text { Diff in means } \\
(95 \% \mathrm{Cl})\end{array}$ & $\begin{array}{l}\text { Diff in means } \\
(95 \% \mathrm{Cl})\end{array}$ \\
\hline \multicolumn{8}{|l|}{ Physical performance } \\
\hline SPPB (points) & $10.1(0.2)$ & $10.7(0.2)$ & $0.6(0.2 \text { to } 0.9)^{* * *}$ & $9.8(0.2)$ & $10.1(0.2)$ & $0.3(0.0$ to 0.6$)$ & $0.6(0.1 \text { to } 1.0)^{*}$ \\
\hline Balance (points) & $3.4(0.1)$ & $3.4(0.1)$ & $0.1(-0.2$ to 0.3$)$ & $3.2(0.1)$ & $3.2(0.1)$ & $0.1(-0.2$ to 0.3$)$ & $0.2(-0.1$ to 0.5$)$ \\
\hline Walk (seconds) & $3.7(0.1)$ & $3.3(0.1)$ & $-0.3(-0.5 \text { to }-0.2)^{* * *}$ & $3.6(0.1)$ & $3.4(0.1)$ & $-0.2(-0.3 \text { to }-0.1)^{* *}$ & $-0.1(-0.2$ to 0.1$)$ \\
\hline Chair (seconds) & $12.7(0.3)$ & $11.0(0.3)$ & $-1.7(-2.2 \text { to }-1.2)^{* * *}$ & $13.3(0.3)$ & $12.8(0.3)$ & $-0.5(-1.0 \text { to }-0.1)^{*}$ & $-1.8(-2.7 \text { to }-0.8)^{* * *}$ \\
\hline 8 foot up-and-go (seconds) & $6.3(0.2)$ & $5.7(0.2)$ & $-0.6(-0.9 \text { to }-0.3)^{* * *}$ & $6.6(0.2)$ & $6.7(0.2)$ & $0.1(-0.2$ to 0.4$)$ & $-1.0(-1.5 \text { to }-0.6)^{* * *}$ \\
\hline \multicolumn{8}{|l|}{ Strength performance } \\
\hline Knee extension (Newton) & $338.8(9.3)$ & $367.3(9.7)$ & $28.5(15.3 \text { to } 41.7)^{* * *}$ & $326.2(9.1)$ & $312.3(9.2)$ & $-13.9(-26.0 \text { to }-1.9)^{*}$ & $55.0(28.4 \text { to } 81.7)^{* * *}$ \\
\hline Hand grip (Newton) & $323.1(8.6)$ & $334.4(8.8)$ & $11.3(1.4 \text { to } 21.2)^{*}$ & $339.0(8.4)$ & $343.1(8.5)$ & $4.1(-4.8$ to 13.1$)$ & $-8.8(-33.1$ to 15.6$)$ \\
\hline \multicolumn{8}{|l|}{ Endurance performance } \\
\hline Six min walking (meter) & $457.0(9.6)$ & $491.1(9.8)$ & $34.2(23.3 \text { to } 45.0)^{* * * *}$ & $449.7(9.3)$ & $447.0(9.4)$ & $-2.7(-12.5$ to 7.1$)$ & $44.2(17.1 \text { to } 71.2)^{* *}$ \\
\hline Physical activity (cpm) & $272.9(16.9)$ & $307.1(15.7)$ & $34.2(0.8 \text { to } 67.6)^{*}$ & $247.0(16.1)$ & 211.7 & $-35.2(-66.2 \text { to }-4.3)^{*}$ & $125.9(96.0$ to M155.8)*** \\
\hline BMI $\left(\mathrm{kg} / \mathrm{m}^{2}\right)$ & $27.7(0.6)$ & $27.3(0.6)$ & $-0.5(-0.7 \text { to }-0.3)^{* * *}$ & $27.0(0.6)$ & $26.9(0.6)$ & $-0.2(-0.4$ to 0.0$)$ & $0.4(-1.2$ to 2.0$)$ \\
\hline Icelandic quality of life (points) & $55.8(0.7)$ & $56.6(0.7)$ & $0.7(-0.2$ to 1.7$)$ & $55.3(0.7)$ & $54.6(0.7)$ & $-0.6(-1.5$ to 0.3$)$ & $1.9(-0.1$ to 3.9$)$ \\
\hline
\end{tabular}

Values are shown as means with standard error (SE) at following time points: baseline and MTI by Group 1 and baseline and repeated baseline by Group 2, 95\% confidence interval in means $(95 \% \mathrm{Cl})$ comparing changes between groups, and significant differences; ${ }^{*} p<.05,{ }^{* *} p<.01,{ }^{* * *} p<.001$.

$\mathrm{MTI}=$ Multimodal Training Intervention.

Rep. Base $=$ Repeat Baseline.

$\mathrm{SE}=$ Standard error.

SPPB $=$ Short physical performance battery.

$\mathrm{cpm}=$ Average counts per minute.

$\mathrm{BMI}=$ Body mass index

maintained (mean diff $=4.2$ Newton, $p>.05$ ) compared to baseline. MTI overall effects in other measurements was following: Balance within SPPB (mean diff $=0.2 \mathrm{~s}, p<.05$ ), $4 \mathrm{~m}$ walking within SPPB (mean diff $=-0.7 \mathrm{~s}, p<.001$ ), chair rises within SPPB (mean diff $=-2.7 \mathrm{~s}, p<.001$ ), hand grip (mean diff $=6.7$ Newton, $p>.05$ ), IQL (mean diff $=0.3$, $p>.05$ ), daily PA (mean diff $=-4.0 \mathrm{cpm}, p>.05$ ) and BMI (mean diff $=-0.6, p<.001)$.

\section{Physical activity behavior}

Figure $3 \mathrm{a}-\mathrm{c}$ illustrates distribution of time spent in daily PA behavior (\%) in terms of walking-days, walkingduration and strength training sessions per week by both groups together during four periods; the period before baseline by Group 1 and delayed baseline by Group 2 (period A); during the immediate intervention by Group 1 and delayed intervention by Group 2 (period B); during the crossover by Group 1 and follow-up 1 by Group 2 (period C); and during follow-up 2 by Group 1 (period D). During period A, approximately half of the participants had none or just one walking day per week and about $60 \%$ estimated that their walking duration per session was less than 15 minutes. The participation in strength training during this period was about $10 \%$. Period B shows the PA behavior over the 6-month immediate and delayed intervention. During period C, $90 \%$ of the participants reported that they had two or more walking days per week, $72 \%$ said that they spent from 16 and up to 75 minutes in every walking session, and $43 \%$ said they performed strength training on a regular basis, generally twice a week. Comparable outcomes during period D in walking days and minutes in walking sessions were measured by Group 1, but $55 \%$ of the group informed that they participated in strength training on a regular basis.

\section{Discussion}

This study resulted in notable significant improvements in functional performance, strength, endurance via $6 \mathrm{MW}, \mathrm{PA}, \mathrm{BMI}$ and IQL among older individuals. At the crossover phase and follow-ups they retained their improvements above baseline status despite some attenuation in strength, IQL and PA. Furthermore, substantially positive changes were seen in participant's lifestyle changes in daily PA behavior, both in endurance and strength training at crossover and follow-up phases. Results from this study clearly demonstrate that well 
Table 3 Outcomes for subjects who completed the crossover and delayed intervention phase, and between-group differences

\begin{tabular}{|c|c|c|c|c|c|c|c|}
\hline \multicolumn{4}{|c|}{ Group 1 (No Intervention) ( $n=45)$} & \multicolumn{3}{|c|}{ Group 2 (Delayed Intervention) $(n=50)$} & \multirow{2}{*}{$\begin{array}{c}\text { Between-group } \\
\text { difference }\end{array}$} \\
\hline Outcome and Values & MTI & Crossover & Change & Rep. Base & Delayed MTI & Change & \\
\hline & $\begin{array}{c}\text { Mean } \\
\text { (SE) }\end{array}$ & $\begin{array}{c}\text { Mean } \\
\text { (SE) }\end{array}$ & $\begin{array}{l}\text { Diff in means } \\
(95 \% \mathrm{Cl})\end{array}$ & $\begin{array}{c}\text { Means } \\
\text { (SE) }\end{array}$ & $\begin{array}{c}\text { Means } \\
\text { (SE) }\end{array}$ & $\begin{array}{l}\text { Diff in means } \\
(95 \% \mathrm{Cl})\end{array}$ & $\begin{array}{l}\text { Diff in means } \\
(95 \% \mathrm{Cl})\end{array}$ \\
\hline \multicolumn{8}{|l|}{ Physical performance } \\
\hline SPPB (points) & $10.7(0.2)$ & $11.0(0.2)$ & 0.3 (0.0 to 0.7$)$ & $10.1(0.2)$ & $10.7(0.2)$ & $0.6(0.2 \text { to } 0.9)^{* * *}$ & $-0.3(-0.8$ to 0.2$)$ \\
\hline Balance (points) & $3.4(0.1)$ & $3.5(0.1)$ & $0.0(-0.2$ to 0.3$)$ & $3.2(0.1)$ & $3.4(0.1)$ & $0.1(-0.1$ to 0.4$)$ & $-0.1(-0.4$ to 0.2$)$ \\
\hline Walk (seconds) & $3.3(0.1)$ & $3.3(0.1)$ & $0.0(-0.2$ to 0.1$)$ & $3.4(0.1)$ & $3.3(0.1)$ & $-0.1(-0.2$ to 0.1$)$ & $0.0(-0.2$ to 0.3$)$ \\
\hline Chair (seconds) & $11.0(0.3)$ & $10.4(0.3)$ & $-0.6(-1.1 \text { to }-0.1)^{*}$ & $12.8(0.3)$ & $11.5(0.3)$ & $-1.3(-1.8 \text { to }-0.8)^{* * *}$ & $1.0(0.1 \text { to } 2.0)^{*}$ \\
\hline 8 foot up-and-go (seconds) & $5.7(0.2)$ & $5.6(0.2)$ & $-0.1(-0.4$ to 0.2$)$ & $6.7(0.2)$ & $6.0(0.2)$ & $-0.7(-1.0 \text { to }-0.4)^{* * *}$ & $0.4(-0.1$ to 0.9$)$ \\
\hline \multicolumn{8}{|l|}{ Strength performance } \\
\hline Knee extension (Newton) & $367.3(9.7)$ & $355.7(9.9)$ & $-11.6(-25.0$ to 1.7$)$ & $312.3(9.2)$ & $343.6(9.6)$ & $31.3(18.6 \text { to } 44.0)^{* * *}$ & $-12.1(-39.4$ to 15.2$)$ \\
\hline Hand grip (Newton) & $334.4(8.8)$ & $335.4(9.0)$ & $1.1(-9.0$ to 11.1$)$ & $343.1(8.5)$ & $357.5(8.7)$ & $14.3(4.9 \text { to } 23.8)^{* *}$ & $22.0(-2.9$ to 46.9$)$ \\
\hline \multicolumn{8}{|l|}{ Endurance performance } \\
\hline Six min walking (meter) & $491.1(9.8)$ & $481.1(10.0)$ & $10.0(-21.3$ to 1.3$)$ & $447.0(9.4)$ & $462.8(9.7)$ & $15.8(5.3 \text { to } 26.3)^{* * *}$ & $-18.3(-46.0$ to 9.5$)$ \\
\hline Physical activity (cpm) & $307.1(15.7)$ & $277.1(16.4)$ & $-30.1(-60.7$ to 0.6$)$ & $211.7(15.0)$ & $337.6(16.0)$ & $125.9(96.0 \text { to } 155.8)^{* * *}$ & $60.6(15.1 \text { to } 106.0)^{* *}$ \\
\hline BMI $\left(\mathrm{kg} / \mathrm{m}^{2}\right)$ & $27.3(0.6)$ & $27.3(0.6)$ & $0.0(-0.2$ to 0.2$)$ & $26.9(0.6)$ & $26.4(0.6)$ & $-0.5(-0.7 \text { to }-0.3)^{* * *}$ & $-0.9(-2.5$ to 0.8$)$ \\
\hline Icelandic quality of life (points) & $56.6(0.7)$ & $56.2(0.7)$ & $-0.4(-1.4$ to 0.6$)$ & $54.6(0.7)$ & $55.5(0.7)$ & $0.9(-0.1$ to 1.8$)$ & $-0.6(-2.7$ to 1.4$)$ \\
\hline
\end{tabular}

Values are shown as means with standard error (SE) at following time points; MTI and crossover by Group 1 and repeated baseline and delayed MTI by Group 2 , $95 \%$ confidence interval in means $(95 \% \mathrm{Cl})$ comparing changes between groups, and significant differences; ${ }^{*} p<.05,{ }^{* *} p<.01,{ }^{* * *} p<.001$.

$\mathrm{MTI}=$ Multimodal Training Intervention

Rep. Base $=$ Repeat Baseline

$\mathrm{SE}=$ Standard error.

$\mathrm{SPPB}=$ Short physical performance battery.

$\mathrm{cpm}=$ Average counts per minute.

$\mathrm{BMI}=$ Body mass index

organized longitudinal multimodal training intervention can improve several physiological as well as psychological factors for relatively long periods among old people.

Age-related trends within studies were remarkably similar and even though the sexes differ in levels of physical fitness, the observed age differences was similar within a given population [24]. The effects from the training intervention in our study showed statistically improvements in functional performance, endurance via $6 \mathrm{MW}$ and strength, PA, BMI and IQL. Similar positive health-related changes have been shown in several other studies [3,4,10-13].

In this study the participants were older and the training intervention and follow-up periods was longer than in most existing multimodal studies of PA that we compare to $[4,8,9]$. Our training design very clearly met the minimum standards recommended in guidelines for older individuals, both in the endurance and strength parts of the study [6,25]. Generally, other multimodal training studies satisfied the strength part of recommendations, but not the endurance part, which results in smaller comprehensive improvements $[10,11,13,26]$. For example, the results from body composition in our study showed that older subjects were able to achieve a decrease in BMI after six months of training, but at the same time enhance their strength. Similar results between this study and the findings of others were seen for gait speed, where functional decline was observed one month after the cessation of training [11].

The frequency, duration, and intensity employed in this study may have contributed to the improvement in $6 \mathrm{MW}$ after the MTI. But the reason for the maintenance at crossover and follow-ups measurements lies arguably in lifestyle changes and self-organized training by the participants after the intervention period. A study [10] with training sessions twice per week showed clearly that this is not enough stimulus for measurable improvements as was evident in our study. Our intervention methods, with about 240 minutes per week of moderateintensity exercise for six months, met the recommended 150 minutes per week of moderate-intensity aerobic activity, for the elderly [6].

These results also underline the importance for older people to participate in regular training for their quality of life [12]. To the knowledge of the authors of the current study, few studies were available where 6-month multimodal training with 6- and 12-month follow-ups has been performed for this age group. In most prior studies, the participants were younger, had significantly 
Table 4 Outcomes for all subjects who completed MTI in both groups

\begin{tabular}{|c|c|c|c|}
\hline \multirow{3}{*}{ Outcome and Values } & \multirow{3}{*}{$\frac{\text { Baseline Repeated baseline }}{\text { Means (SE) }}$} & \multirow{3}{*}{$\frac{\frac{\text { Completed MTI }(n=98)}{\text { Immediate MTI Delayed MTI }}}{\text { Means (SE) }}$} & \multirow[b]{2}{*}{ Change } \\
\hline & & & \\
\hline & & & Diff in means $(95 \% \mathrm{Cl})$ \\
\hline \multicolumn{4}{|l|}{ Physical performance } \\
\hline SPPB (points) & $10.2(0.1)$ & $10.7(0.1)$ & $0.6(0.3 \text { to } 0.8)^{* * *}$ \\
\hline Balance (points) & $3.3(0.1)$ & $3.4(0.1)$ & 0.1 (-0.1 to 0.3$)$ \\
\hline Walk (seconds) & $3.5(0.1)$ & $3.3(0.1)$ & $-0.2(-0.3 \text { to }-0.1)^{* * *}$ \\
\hline Chair (seconds) & $12.6(0.2)$ & $11.1(0.2)$ & $-1.5(-1.8 \text { to }-1.1)^{* * *}$ \\
\hline 8 foot up-and-go (seconds) & $6.4(0.1)$ & $5.7(0.1)$ & $-0.6(-0.8 \text { to }-0.4)^{* * *}$ \\
\hline \multicolumn{4}{|l|}{ Strength performance } \\
\hline Knee extension (Newton) & $332.2(7.2)$ & $360.8(7.2)$ & $28.6(18.7 \text { to } 38.5)^{* * *}$ \\
\hline Hand grip (Newton) & $336.0(6.4)$ & $349.0(6.4)$ & $13.0(5.8 \text { to } 20.2)^{* * *}$ \\
\hline \multicolumn{4}{|l|}{ Endurance performance } \\
\hline Six min walking (meter) & $457.5(7.5)$ & $482.4(7.5)$ & $24.9(17.2 \text { to } 32.6)^{* * *}$ \\
\hline Physical activity (cpm) & $240.3(12.2)$ & $326.0(11.6)$ & $85.6(62.2 \text { to } 109.1)^{* * *}$ \\
\hline BMI $\left(\mathrm{kg} / \mathrm{m}^{2}\right)$ & $27.3(0.5)$ & $26.8(0.5)$ & $-0.46(-0.6 \text { to }-0.3)^{* * *}$ \\
\hline Icelandic quality of life (points) & $55.6(0.5)$ & $56.4(0.5)$ & $0.8(0.1 \text { to } 1.5)^{*}$ \\
\hline
\end{tabular}

Values are shown as means with standard error (SE) at following time points pulled together: baseline by Group 1 and repeated baseline by Group 2, and immediate MTI by Group 1 and delayed MTI by Group 2, and as $95 \%$ confidence interval in means (95\% Cl) comparing changes for all subjects who completed MTI, and significant differences; ${ }^{*} p<.05,{ }^{* *} p<.01,{ }^{* * *} p<.001$.

$\mathrm{MTI}=$ Multimodal training intervention.

$\mathrm{SE}=$ Standard error.

$\mathrm{SPPB}=$ Short physical performance battery.

$\mathrm{cpm}=$ Average counts per minute.

$\mathrm{BMI}=$ Body mass index

worsened at the follow-up measurements, and were even worse after one year of follow-up compared to their baselines $[9,10]$. Overall MTI outcomes in our study generally remained statistically better compared to baseline, and none were statistically lower. These long-term positive results are likely to have three main reasons. First, the use of reasonable and progressive training protocol with a desirable balance between the appropriate volume and intensity of the training sessions throughout the whole intervention period. Secondly, the ability of the participants to follow the main goals of this study: to stay independent and carry on with the PA after the MTI, and finally, the guidance part by health instructors, both in educating and encouraging the participants in their work. The validity of the last point needs further examination. In addition, the exercise program after MTI could be continued by the participants with less support from a health instructor. Instead of twelve to sixteen exercise sessions with a health instructor per month, we would recommend, based on our findings, two to four sessions with a health instructor per month, in addition, independent PA, to maintain endurance and strength.

This multimodal training intervention study had 6 and 12 months follow-up time-points. The results clearly demonstrated that this multimodal training program improved endurance as well as strength performance, decreased BMI and increased and maintained IQL in older individuals for a relatively long period of time. Hence, this type of training could have a clinically relevant impact on older individuals in the general population if applied to a large number of individuals. The use of educated health instructors during the training intervention and working closely with the people might help to maintain their performance after the formal training period. Such implementation seems to motivate and support older individuals who seek to maintain their physical health and IQL on their own over a long period of time. This was strongly supported by the observation that about $60 \%$ of the participants estimated that their walking duration per session was less than 15 minutes before they entered the study. On the other hand, about $90 \%$ had two to seven walking days per week, whereof over $70 \%$ said that they spent from 16 and up to 75 minutes in every walking session for up to a year after the training intervention.

This study had several strengths that address some of the limitations of previous multimodal training studies. Our objective was to influence participants' lifestyles and everyday activities during the MTI, with a focus on individual responsibility and to prepare the participants to train independently after completing the immediate or 


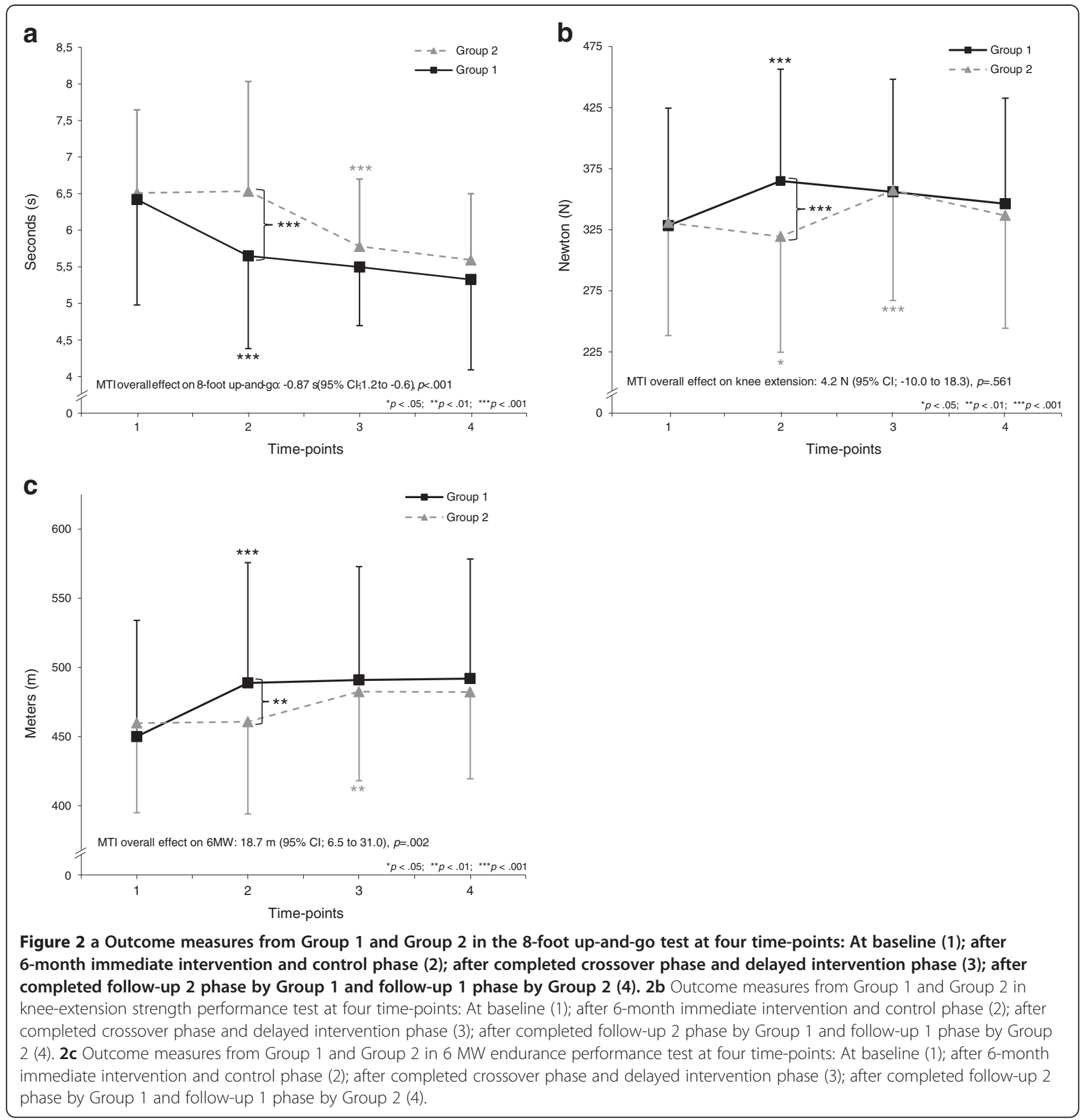

the delayed intervention phase. Our training was based on international recommendations [27] and the methods and philosophy were similar to those that would be used in a sedentary population, with few allowances for age. The use of accelerometers to assess physical activity volume and intensity and the low dropout rate for this agegroup can be classified as strength of this study.

\section{Conclusions}

In conclusion, this study clearly demonstrates that multimodal training intervention based on endurance and strength exercise is feasible and beneficial in older populations, particularly among those who have not been physically active before. Our results suggest that regular MTI can affect and improve long-term retention, 12 and 18 months after the baseline measurements, of functional fitness and endurance performance measured by $6 \mathrm{MW}$ and maintain strength performance and quality of life in old people. In addition, the intervention can influence the lifestyle behavior concerning strength and endurance training. Therefore, we suggest that regular MTI can prevent 


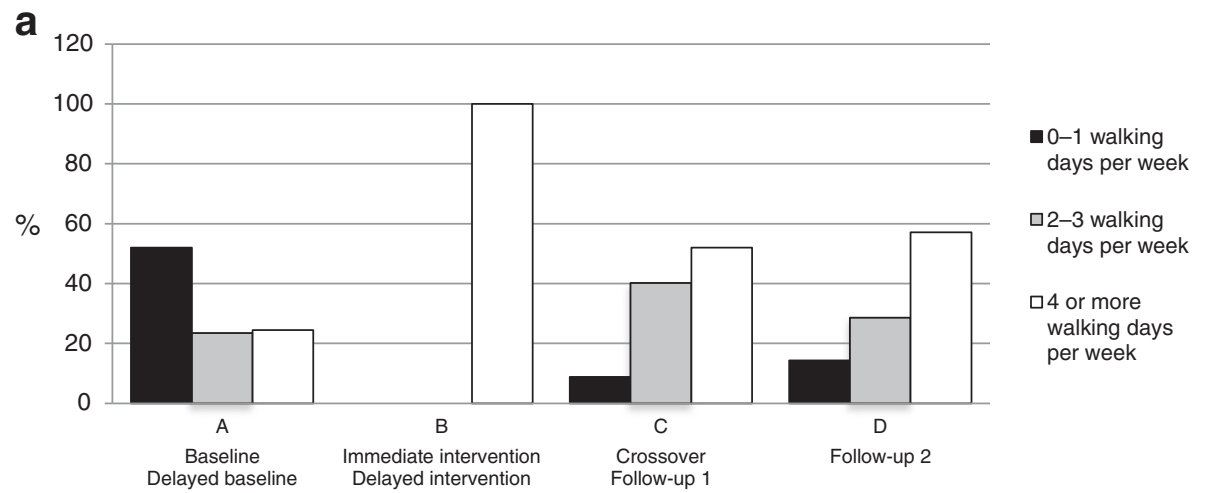

Walking days during four periods

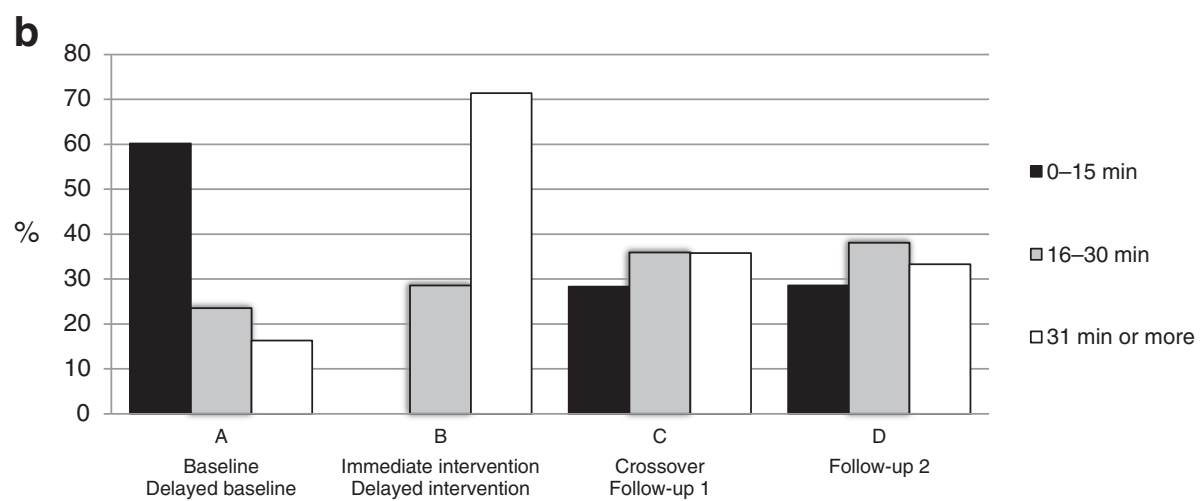

Walking duration per walking day in a week during four periods

C

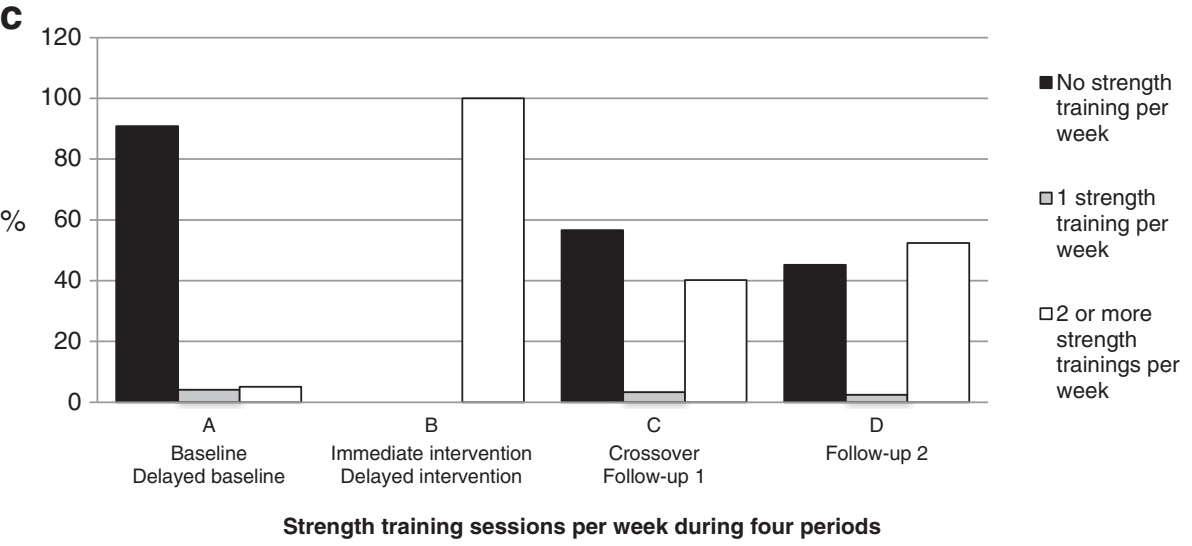

Figure 3 a Distribution of participation spent in physical activity, walking days in a week (\%), during following four periods for both groups: During the period before baseline and delayed baseline (A), during immediate intervention and delayed intervention (B), during crossover and follow-up 1 (C) and during follow-up 2 by Group 1 (D). 3b Distribution of participation spent in physical activity, walking duration per walking day in a week (\%), during following four periods for both groups: During the period before baseline and delayed baseline (A), during immediate intervention and delayed intervention (B), during crossover and follow-up 1 (C) and during follow-up 2 by Group 1 (D). 3c Distribution of participation spent in physical activity, strength training sessions per week (\%), during following four periods for both groups: During the period before baseline and delayed baseline (A), during immediate intervention and delayed intervention (B), during crossover and follow-up 1 (C) and during follow-up 2 by Group 1 (D).

decline in functional fitness in old people, influence their lifestyle and positively affect their ability to stay independent; thus reducing the need for institutional care. For societies and individual health practitioners it is therefore important to encourage all older persons to increase their PA and give them opportunities to participate in a supervised multimodal training program. 


\section{Abbreviations}

PA: Physical activity; MTI: Multimodal training intervention; SPPB: Short Physical Performance Battery; IQL: Icelandic quality of life; HRQL: The healthrelated quality of life; BMI: Body mass index; $6 \mathrm{MW}$ : 6-minute walk test.

\section{Competing interests}

The authors declare that they have no competing interest.

\section{Authors' contributions}

All authors were involved in the study concept and design, and in obtaining funding. JG, EJ, and VG were involved in the acquisition of data, and JG, EJ, SAA, ASO, TH, KS, VG, TA, and PVJ were involved in analysis and interpretation of data. All authors drafted the manuscript and critically revised it for important intellectual content. All authors read and approved the final manuscript.

\section{Acknowledgments}

We thank all participants for their understanding and cooperation. We thank the research team at the University of Iceland and, especially the Master's Students that contributed in the data collection and the research colleague at the National Institute of Aging in Bethesda, USA

\section{Funding}

This research project was supported by The Icelandic Centre for Research, The University of Iceland Research Fund, The Ministry of Education, Science and Culture Sport Fund, The Association of Municipalities in the Capital Area, The Fitness Centre Laugar, The Public Health Institute of Iceland and The Icelandic Heart Association.

\section{Author details}

${ }^{1}$ Centre for Research in Sport and Health Sciences, University of Iceland, Laugarvatn, Iceland. ${ }^{2}$ Icelandic Heart Association, Reykjavik, Iceland. ${ }^{3}$ Faculty of Medicine, University of Iceland, Reykjavik, Iceland. ${ }^{4}$ Department of Geriatrics, Landspitali - University Hospital, Reykjavik, Iceland. ${ }^{5}$ Laboratory of Epidemiology, Demography and Biometry, Intramural Research Program, National Institute of Aging, Baltimore, MD, USA

Received: 21 October 2011 Accepted: 4 September 2012 Published: 10 September 2012

\section{References}

1. Nylen ES, Kokkinos P, Myers J, Faselis C: Prognostic effect of exercise capacity on mortality in older adults with diabetes mellitus. J Am Geriat Soc 2010, 58:1850-4

2. Ouslander JG, Griffiths PC, McConnell E, Riolo L, Kutner M, Schnelle J: Functional incidental training: a randomized, controlled, crossover trial in Veterans Affairs nursing homes. J Am Geriatr Soc 2005, 53:1091-100.

3. Strasser B, Keinrad M, Haber P, Schobersberger W: Efficacy of systematic endurance and resistance training on muscle strength and endurance performance in elderly adults-a randomized controlled trial. Wien Klin Wochenschr 2009, 121:757-64.

4. Toraman NF, Erman A, Agyar E: Effects of multicomponent training on functional fitness in older adults. J Aging Phys Act 2004, 12:538-53.

5. Stewart KJ: Physical activity and aging. Ann N Y Acad Sci 2005 1055:193-206

6. American College of Sports M, Chodzko-Zajko WJ, Proctor DN, Fiatarone Singh MA, Minson CT, Nigg CR, Salem GJ, Skinner JS: American College of Sports Medicine position stand. Exercise and physical activity for older adults. Med Sci Sports Exerc 2009, 41:1510-30.

7. Baker MK, Atlantis E, Fiatarone Singh MA: Multi-modal exercise programs for older adults. Age Ageing 2007, 36:375-81.

8. Toraman NF: Short term and long term detraining: is there any difference between young-old and old people? Br J Sports Med 2005, 39:561-4.

9. Toraman NF, Ayceman N: Effects of six weeks of detraining on retention of functional fitness of old people after nine weeks of multicomponent training. Br J Sports Med 2005, 39:565-8.

10. Carvalho MJ, Marques E, Mota J: Training and detraining effects on functional fitness after a multicomponent training in older women. Gerontology 2009, 55:41-8.
11. Tokmakidis SP, Volaklis KA: Training and detraining effects of a combinedstrength and aerobic exercise program on blood lipids in patients with coronary artery disease. J Cardiopulm Rehabil 2003, 23:193-200.

12. Teixeira-Salmela LF, Santiago L, Lima RC, Lana DM, Camargos FF, Cassiano JG: Functional performance and quality of life related to training and detraining of community-dwelling elderly. Disabil Rehabil 2005 , 27:1007-12

13. Toraman F, Sahin G: Age responses to multicomponent training programme in older adults. Disabil Rehabil 2004, 26:448-54.

14. Haskell WL, Lee IM, Pate RR, Powell KE, Blair SN, Franklin BA, Macera CA, Heath GW, Thompson PD, Bauman A, American College of Sports M, American Heart A: Physical activity and public health: updated recommendation for adults from the American College of Sports Medicine and the American Heart Association. Circulation 2007, 116:1081-93.

15. Harris TB, Launer LJ, Eiriksdottir G, Kjartansson O, Jonsson PV, Sigurdsson G, Thorgeirsson G, Aspelund T, Garcia ME, Cotch MF, Hoffman HJ, Gudnason V: Age, Gene/Environment Susceptibility-Reykjavik Study: multidisciplinary applied phenomics. Am J Epidemiol 2007, 165:1076-87.

16. Guralnik JM, Simonsick EM, Ferrucci L, Glynn RJ, Berkman LF, Blazer DG, Scherr PA, Wallace RB: A short physical performance battery assessing lower extremity function: association with self-reported disability and prediction of mortality and nursing home admission. J Gerontol 1994, 49:M85-94.

17. Karvonen J, Vuorimaa T: Heart rate and exercise intensity during sports activities. Practical application. Sports Med 1988, 5:303-11.

18. Rikli RE, Jones $\mathrm{CJ}$ : Development and validation of a funcional fitness test for comunity residing older adults. J Aging Phys Activ 1999, 7:129-61.

19. Dey DK, Bosaeus I, Lissner L, Steen B: Changes in body composition and its relation to muscle strength in 75-year-old men and women: a 5-year prospective follow-up study of the NORA cohort in Goteborg, Sweden. Nutrition 2009, 25:613-9.

20. Butland RJ, Pang J, Gross ER, Woodcock AA, Geddes DM: Two-, six-, and 12-minute walking tests in respiratory disease. Br Med J 1982, 284:1607-8.

21. Copeland $J \mathrm{~L}$, Esliger DW: Accelerometer assessment of physical activity in active, healthy older adults. J Aging Phys Act 2009, 17:17-30.

22. Bull FC, Maslin TS, Armstrong T: Global physical activity questionnaire (GPAQ): nine country reliability and validity study. J Phys Act Health 2009, 6:790-804.

23. Bjornsson JK, Tomasson K, Ingimarsson S, Helgason T: Health-related quality of life of psychiatric patients in Iceland: Psychometric properties of the IQL. Nord J Psychiatry 1997, 51:183-91.

24. Talbot LA, Metter EJ, Fleg JL: Leisure-time physical activities and their relationship to cardiorespiratory fitness in healthy men and women 18-95 years old. Med Sci Sports Exerc 2000, 32:417-25.

25. Nelson ME, Rejeski WJ, Blair SN, Duncan PW, Judge JO, King AC, Macera CA Castaneda-Sceppa C: Physical activity and public health in older adults: recommendation from the American College of Sports Medicine and the American Heart Association. Med Sci Sports Exerc 2007, 39:1435-45.

26. Nelson ME, Layne JE, Bernstein MJ, Nuernberger A, Castaneda C, Kaliton D, Hausdorff J, Judge JO, Buchner DM, Roubenoff R, Fiatarone Singh MA: The effects of multidimensional home-based exercise on functional performance in elderly people. J Gerontol A Biol Sci Med Sci 2004 59:154-60.

27. Kokkinos P, Myers J, Faselis C, Panagiotakos DB, Doumas M, Pittaras A, Manolis A, Kokkinos JP, Karasik P, Greenberg M, Papademetriou V, Fletcher R: Exercise capacity and mortality in older men: a 20-year follow-up study. Circulation 2010, 122:790-7.

doi:10.1186/1479-5868-9-107

Cite this article as: Gudlaugsson et al: Effects of a 6-month multimodal training intervention on retention of functional fitness in older adults: $A$ randomized-controlled cross-over design. International Journal of Behavioral Nutrition and Physical Activity 2012 9:107. 